Research Article

\title{
Novel Approach to Handling Microfiber-Rich Dye Effluent for Sustainable Water Conservation
}

\author{
R. Dharmaraj, ${ }^{1}$ Alagar Karthick $\mathbb{D}^{2},{ }^{2}$ G. K. Arunvivek, ${ }^{3}$ S. Gopikumar, ${ }^{4}$ V. Mohanavel ${ }^{5},{ }^{5}$ \\ M. Ravichandran (iD, ${ }^{6}$ and Murugesan Bharani ${ }^{7}{ }^{7}$
}

${ }^{1}$ Department of Civil Engineering, KPR Institute of Engineering and Technology, Coimbatore, Tamil Nadu 641407, India
${ }^{2}$ Department of Electrical and Electronics Engineering, KPR Institute of Engineering and Technology, Coimbatore,
Tamil Nadu 641407, India
${ }^{3}$ Department of Civil Engineering, Karpagam College of Engineering, Coimbatore, Tamil Nadu, India
${ }^{4}$ Department of Civil Engineering, SCAD College of Engineering and Technology, Tirunelveli, Tamil Nadu, India
${ }^{5}$ Centre for Materials Engineering and Regenerative Medicine, Bharath Institute of Higher Education and Research, Chennai,
Tamil Nadu 600073, India
${ }^{6}$ Department of Mechanical Engineering, K. Ramakrishnan College of Engineering, Trichy, Tamil Nadu 621112, India
${ }^{7}$ School of Textile, Leather and Fashion Technology, Kombolcha Institute of Technology, Wollo University, South Wollo, Ethiopia

Correspondence should be addressed to Murugesan Bharani; bharani.murugesan@kiot.edu.et

Received 3 May 2021; Accepted 26 June 2021; Published 6 July 2021

Academic Editor: Alessio Cascardi

Copyright (C) 2021 R. Dharmaraj et al. This is an open access article distributed under the Creative Commons Attribution License, which permits unrestricted use, distribution, and reproduction in any medium, provided the original work is properly cited.

\begin{abstract}
The replacement of substances that favor the manufacturing of utility blocks ingredients is unpredictable in modern research. The experimental approach structured for the present investigation considered partial substitution of the cement mantle of a concrete matrix with dried fly ash sediment powder. As exploring innovation in being treated, dye wastewater is used in place of precious potable water for preparing mix ratio. The experimental outcomes were strongly supported by a regression representation at a macrolevel analysis and a scanning electron microscopy analysis at a microstructural level. The correlation coefficient of the developed mathematical models exhibited a dependable correlation of more than $90 \%$. This shows the reliability of the developed regression equation for base strength predictions. Accordingly, the eventual safer and optimal limit of proportioning such a foreign matter like the dried fly ash sediment powder usage is controlled, not exceeding $9 \%$ by weight of cement mantle. However, due to the infused sediment particles within the treated effluents, the potable water is $100 \%$ replaced without sacrificing the basic quality. The administration of this dye effluent in artificially constructed wetland methods is designed for sustainable water conservation.
\end{abstract}

\section{Introduction}

Urbanization and industrialization in developing countries utilize their human resources for economic growth in which the textile industries are part of the team. The life cycle of the textile industry and their contribution to societies are endless; meanwhile, their contributions to environmental pollution are countless [1]. Recent research outcomes reveal the wonderful source of microfibers available in the textile dye effluents, which are less noticed and utilized $[2,3]$. With the biggest population in the world, India excels in the textile industry in manufacturing and marketing as it limelighted as a pioneer in this sector with the production of the largest processed sludge [4]. The wastewater generated from these sectors is treated in a distinctive way to remove color and recycling of water [5]. As excess sludge generation and effluent quantity from the industry are acceptable by the state pollution control board, there arises a novel technique in converting the waste as raw material, and they are planned to be added as supporting components for the construction industry [6]. This work has been scheduled to design a nextgeneration low-cost concrete block using dye wastewater [7]. 
Inappropriate discarding of the waste mentioned above into the waterway may cause the growth of biological nutrients that leads to contamination and has shown how it can cause irreversible damage to the environment in the vicinity [8]. Meanwhile, the environment is under increasing pressure from this emanating sludge and other wastes of the textile industry [9].

The basic needs of humanity's survival worldwide always revolve around basic amenities, food, fiber, and shelter. Even as the agricultural sector takes off the food production and the construction arena caters to shelter needs, the fiber requirements for cultural cover-up solely depend on textile industries. The exponential growth of population warrants a geometrical progression in the textile arena to narrow down the demand-supply gap $[10,11]$. However, the industrial textile growth in tandem with the technological advancements and creative processors in the modern era inevitably generates a significant effluent measure. These effluents, mostly originating from the textile processing units, including the dyeing faction, turn hazardous if they are passed on into the soil without treatment or diverted into the water bodies as point source pollution or distributed source pollution during the stormy periods. The difficulty arising out is to explore how best these hazardous industrial wastes are moderated and transformed for a possible recycling within the construction arena as an alternative and equal building material $[12,13]$.

The perils associated with the dyeing faction are the unwarranted production of some of the toxic chemicals such as naphthol, sulfur, acetic acid, and nitrates; vat dyes; enzymes; chromium compounds; soaps; heavy metals like arsenic, cadmium, lead, mercury, cobalt, nickel, and copper; certain auxiliary chemicals; formaldehyde-based dye fixing agents; hydrocarbon-based softeners; non-biodegradable dyeing chemicals; and chlorinated stain removers. Suppose such toxic elements are unscrupulously dumped on productive lands or diluted into potential water bodies. These toxic elements alter the physiochemical properties of both soil and water to become unproductive and infertile. They naturally contaminate the soil and water resources, and the noxious gases liberated will also lead to air pollution. Due to mounting pressures from governmental and nongovernmental organizations against pollution, contamination, and degradation of our environment, legal implications by ordinance have been levied on the textile industry units to scrupulously follow the technological socioeconomic guidelines to make their industrial premise as a zero-pollution zone [14-16]. Hence, it becomes imperative for the textile industry to install the primary, secondary, and tertiary units to treat the effluents incurring relatively huge installation, operation, and maintenance costs.

The problem arising out of these components is alleviated if these waste byproducts are transformed into an alternate but equal building material by partial substitution mode or total replacement of the conventional materials $[15,17]$. Hence, the conceptual perspectives can replace costlier treatment units and processes by transforming these waste materials into promising substitution materials for the construction arena. Giving way to environmentally friendly and cost-effective solutions naturally brings down the burden on textile industries. Besides these technoeconomic aspects, the conceptual perspectives will also envisage strategies for social acceptability based on the environmental safety endorsement $[2,18]$. The researchers and planners are also contemplating using the thermal power plant waste byproducts predominantly in fly ash to act as a coagulant to treat the raw effluent generated $[19,20]$. Such lateral thinking for the usage of fly ash opens the flood gate for cost-effective technology in capturing the toxic and hazardous waste elements to get converted into a sustainable building material fraction $[21,22]$.

In this work, utility block productions are carried out with the treated textile effluents as the commonly available class F fly ashes are used as a coagulant. The proportions of this coagulant fly ash are added to get the properties of the supernatant solution to match those of the potable water in utility block production. Considering this fact, arbitrary trial-and-error proportions are framed to evaluate the supernatant solution as equal to potable water.

\section{Materials and Methods}

The empirical proposition related to the technoeconomic possibility of applying technical knowledge on treated textile effluent fractions from the textile sector is furnished below. The procedural sequences related to the influences of effluent fractions proliferating through the concrete matrix of the utility blocks towards the end of manufacturing cost-effective and eco-friendly concrete mixes are elaborated.

As the first step, the present experimentation involves using Class F fly ash obtained from Mettur Thermal Power Plant, Tamil Nadu, India, as a coagulant in treating the textile effluents to get at the supernatant solution in place of potable water. The second step involves using the settled coagulant fly ash, after proper oven drying, as a partial substitution material for ordinary Portland cement (OPC), with particular note to making of utility such as the paver blocks and lining blocks. Table 1 furnishes the properties of the coagulant fly ash and OPC.

The experimentation involves stepwise addition of fly ash for coagulation at $5 \%, 10 \%, 15 \%, 20 \%$, and $25 \%$ by weight of effluent, and the treatments are denoted as TFA1, TFA2, TFA3, TFA4, and TFA5 in a row [23].

2.1. Experimental Setup. The causes for the present investigation are to develop a low-cost utility block adapting the technological innovation. The usage of dyeing effluent acts as a determining agent to find out the compatibility of dried fly ash sediment sludge in this proportion. Simultaneously the textile effluent optimal proportion, which acts as a replacement, is determined in this experiment. In the first phase, the natural dyeing effluent collected from the textile industry is subjected to sedimentation aided by the coagulation process. Using clariflocculator, dyeing effluents are flocculated with fly ash coagulant. The contact time of 30 minutes for the coagulation process is kept constant for all treatments. 
TABle 1: Property of coagulant fly ash and ordinary Portland cement.

\begin{tabular}{lccc}
\hline S. no. & Description & OPC & Coagulant fly ash \\
\hline 1 & Specific gravity & 3.21 & 2.23 \\
2 & $\mathrm{SiO}_{2}$ & 20.28 & 59.73 \\
3 & $\mathrm{Al}_{2} \mathrm{O}_{3}$ & 5.72 & 29.67 \\
4 & $\mathrm{Fe}_{2} \mathrm{O}_{3}$ & 2.71 & 0.96 \\
5 & $\mathrm{CaO}$ & 62.75 & 1.21 \\
6 & $\mathrm{MgO}$ & 2.48 & 1.34 \\
7 & $\mathrm{SO}_{3}$ & 1.92 & 4.52 \\
8 & $\mathrm{~N}_{2} \mathrm{O}$ & 0.19 & 0.43 \\
9 & $\mathrm{~K}_{2} \mathrm{O}$ & 0.84 & 1.19 \\
\hline
\end{tabular}

The compressive and flexural strength variations of treated effluent merged concrete blocks are tested for various proportions of fly ash sludge replacing the cement in the ratios of $3,6,9,12$, and $15 \%$ by weight cement. To identify the compressive and flexural strength of the control and treated textile effluent, dried fly ash utility blocks, the sizes $200 \mathrm{~mm} \times 100 \mathrm{~mm} \times 60 \mathrm{~mm}$ are cast and tested after 3, 7, and 28 days of curing spells [24]. The mix ratios are displayed in Table 2.

In the determination of compressive strength, the axial compressions test is conducted. Similarly, three-point flexural strength tests are conducted to find the flexural strength of the conventional and improved utility blocks. The tests' setup of three-point flexural strength are highlighted in Figure 1.

All the experimental procedures are followed as per Indian standards, and the outcome of the results is categorized for commercial applications.

2.2. Constructed Wetland Design. Constructed wetlands are designed in such a way that they are directly exposed to the atmosphere and sunlight. This model has an anaerobic, anoxic zone that withstands high loading rates, which are normally adopted after secondary or tertiary treatment [25].

\section{Results and Discussion}

3.1. Comparison of Chemical Properties of Potable Water and Treated Effluent. The prominent influencing factors such as $\mathrm{pH}$, Total Dissolved Solids (TDS), chlorides, and sulphates are measured for various dosages of fly ash are experimented with for the coagulation process. The data from the clariflocculations are compared with permissible limits prescribed as per IS 456: (2000) [26]. Table 2 furnishes the chemical properties of potable water and treated effluent with varying dosages of fly ash coagulant. The experimental results showed that all the parameters except TDS for $20 \%$ fly ash coagulant dosage were within the permissible limits. Since TDS parameters are a superior-strength influencing factor in the concrete matrix, the coagulant dosages are extended to $25 \%$ by the weight of the effluent [27]. From the experimental observations, the optimal coagulant dosages of fly ash are identified as $25 \%$ by weight of the effluent (TFA5) listed in Table 3.
3.2. Comparison of Compressive Strength. Sufficient time lapse under curing is essential for any concrete to meet its greatest possible strength. The conventional practice is scheduled to assess the strength of the concrete subjected to curing, at an earlier stage of 3-day curing spell, a nominal stage of 28 days curing spell, and next to the last stage of 56 days or more. However, the attainment of strength with respect to each curing day lapse is periodically assessed between the early stage and the final stage. Meanwhile, by the interpolation technique, the higher time lapses exceeding the final stage are extrapolated. The compressive strength variations of conventional concrete utility blocks for different curing spells are shown in Figures 2 and 3.

In evaluating the strength of concrete during the entire curing period, the interpolation techniques with the support of empirical regressions are approached [28].

Accordingly, a simple linear equation by the regression is established for potable water usage as $y=0.5094 x+16.59$.

This prediction equation reveals that by backward extrapolation, an ordinate value of $16.59 \mathrm{MPa}$ above which only a linear rate of increase in strength of concrete is obtained as 0.5094 MPa per day with a correlation coefficient $R^{2}=0.91$. The increase in the strength per day is interpolated using a regression equation or by cutting the graphical curve obtained obeying this regression path. Rendering to this equation, the maximum compressive strength attained at 28 days is examined and evaluated as $31 \mathrm{MPa}$ against a design value of $30 \mathrm{MPa}$ as shown in Figure 4.

In the case of the treated effluent water, the presence of minute suspended sediments is unavoidable, but the same might be helpful in filling up the concrete pores to enhance the strength. This null hypothesis has been proved from experimental observation backed up by linear regression. In this case, the base strength attained at the starting of curing for the fresh concrete is analyzed as $17.52 \mathrm{MPa}$, above which the rate of increase in strength is identified as $0.485 \mathrm{MPa}$ per day towards the nominal, the penultimate, and the ultimate curing spells. Compared to the conventional concrete, the improvised concrete imbibed with treated effluent water has shown an enhanced base strength of $17.52 \mathrm{MPa}$ against 16.591 MPa. The subsequent increase attainable by improvised concrete is predicted as $0.485 \mathrm{MPa}$ per day as against $0.509 \mathrm{MPa}$ per day (Hayat et al., 2015). A consequent reduction in the apparent porosities was observed due to proliferating dissolved particles in the effluent. This initial escalation in the value of base strength at $17.52 \mathrm{MPa}$ has helped the improvised concrete keep up relatively higher strengths at all curing stages over and above those of conventional concrete utility blocks.

3.3. Comparison of Flexural Strength. The flexural strength test for the improvised block considers the conventional concrete mix as the control for comparison. In relation to the empirical regression model $y=0.0513 x+2.9774$, the initial flexural strength attained at the beginning of curing is identified as $2.902 \mathrm{MPa}$ with a steady increasing rate of $0.045 \mathrm{MPa}$ per day. Regarding the control mix, the largest flexural strength attained at 28 days was found evaluated as 
Table 2: Mix calculation of cubes.

\begin{tabular}{lccccccc}
\hline $\begin{array}{l}\text { S. } \\
\text { no. }\end{array}$ & $\begin{array}{c}\text { Cubes } \\
\text { mould }\end{array}$ & $\begin{array}{c}\text { Percentage of fly ash } \\
(\%)\end{array}$ & $\begin{array}{c}\text { Cement } \\
(\mathrm{kg})\end{array}$ & $\begin{array}{c}\text { Textile waste } \\
(\mathrm{kg})\end{array}$ & $\begin{array}{c}\text { Fine aggregate } \\
(\mathrm{kg})\end{array}$ & $\begin{array}{c}\text { Textile sludge } \\
(\mathrm{kg})\end{array}$ & $\begin{array}{c}\text { Coarse aggregate } \\
(\mathrm{kg})\end{array}$ \\
\hline 1 & 1 & 0 & 1 & 0.21 & 1.7 & 0 & 3.9 \\
2 & 4 & 3 & 1 & 0.21 & 1.7 & 0.3 & 3.6 \\
3 & 4 & 6 & 1 & 0.21 & 1.7 & 0.6 & 3.3 \\
4 & 4 & 9 & 1 & 0.21 & 1.7 & 0.9 & 3.2 \\
5 & 4 & 12 & 1 & 0.21 & 1.7 & 1.2 & \\
6 & 3 & 15 & 1 & 0.21 & 1.7 & 1.5 & 2.9 \\
\hline
\end{tabular}

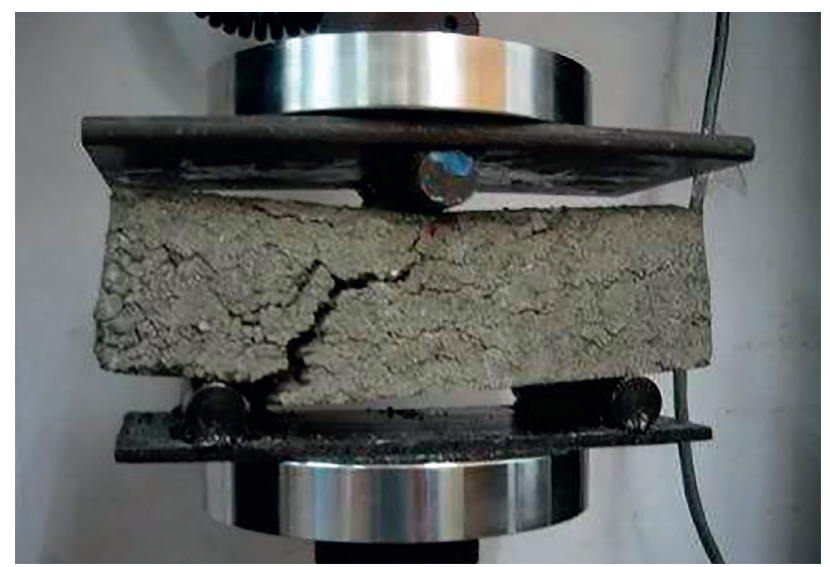

FIgURE 1: Experimentation on three-point load flexural strength.

TABLe 3: Chemical composition of potable water and treated effluent.

\begin{tabular}{|c|c|c|c|c|c|c|c|c|c|}
\hline S. no. & Parameter & Permissible limit (IS456, 2000) & Potable water & Dyeing effluent & TFA1 & TFA2 & TFA3 & TFA4 & TFA5 \\
\hline 1 & $\mathrm{pH}$ & $>6$ & 7.76 & 9.29 & 8.96 & 8.57 & 8.21 & 7.97 & 7.62 \\
\hline 2 & TDS (mg/L) & 2000 & 1052 & 10839 & 8869 & 7029 & 5642 & 2905 & 1088 \\
\hline 3 & Chloride $(\mathrm{mg} / \mathrm{L})$ & 1000 & 142 & 4760 & 3844 & 2276 & 1422 & 973 & 370 \\
\hline 4 & Sulphate (mg/L) & 400 & 138 & 461 & 427 & 311 & 247 & 198 & 146 \\
\hline
\end{tabular}

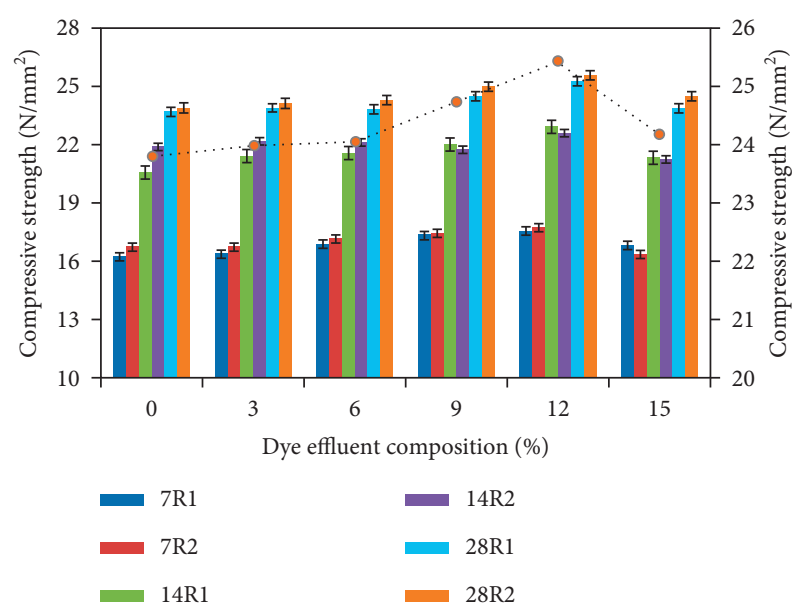

FIgUre 2: Compressive strength of dye effluent.

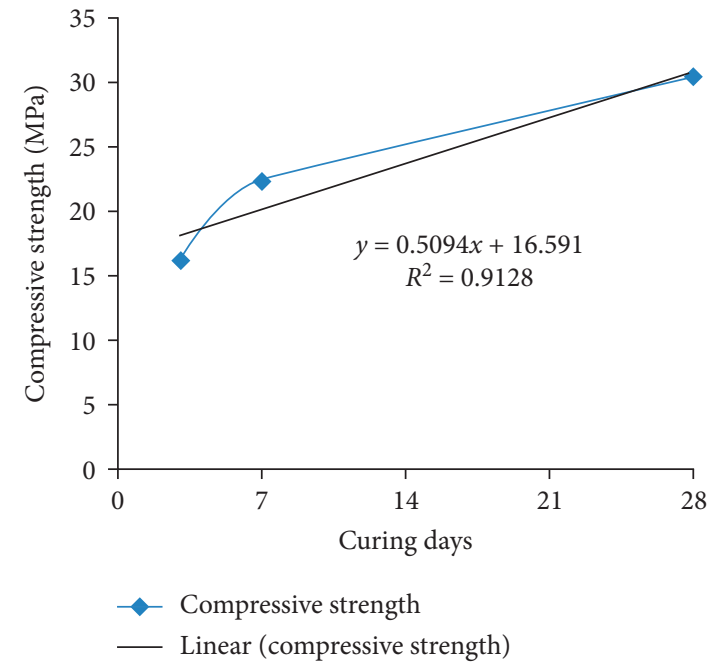

FIgURE 3: Temporal variations in compressive strength of the conventional concrete block. 


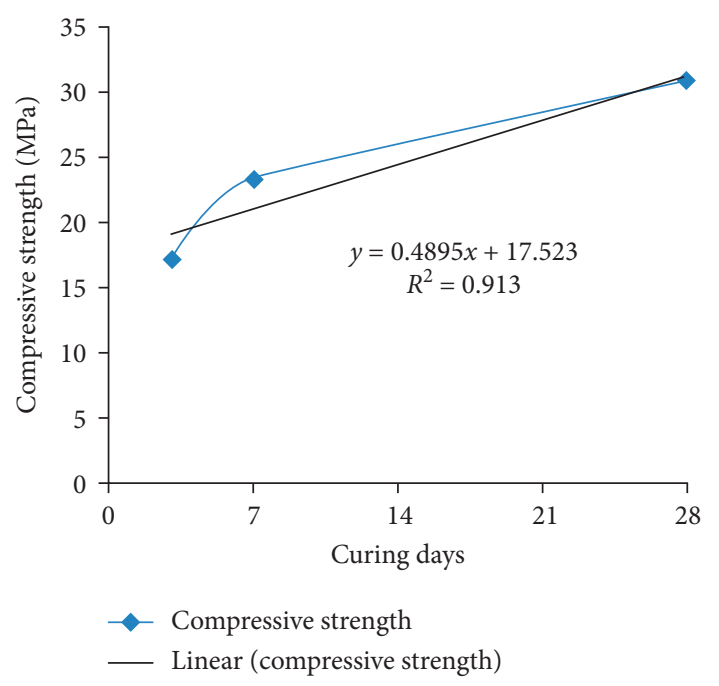

FIGURE 4: Temporal variations in compressive strength of treated effluent imbibed concrete block.

4.14 MPa. The flexural strength of conventional concrete blocks for 3, 7, and 28 days of curing spells is highlighted in Figure 5.

The test result reveals that qualitative properties for improvised concrete block upon imbibing treated effluent showed an increasing trend for curing spells of 3, 7, and 28 days. Based on the developed mathematical model, the base flexural strength of treated effluent imbibed concrete utility block is evaluated as $2.977 \mathrm{MPa}$ with a constant increase rate of $0.051 \mathrm{MPa}$ per day at a dependable correlation of $R^{2}=0.94$. The flexural strength of treated effluent merged with utility block after 28 days of curing is identified as $4.38 \mathrm{MPa}$ which are slightly higher than those of control concrete blocks [29]. The strength increase might be due to the accumulation of fine suspended particles through the interpores of the concrete, which tends to decrease the porosity and crack propagation in the concrete matrix. Flexural strength variation of treated effluent imbibed concrete block for 3,7 , and 28 days of curing spells is displayed in Figure 6.

3.4. Compressive Strength Compared with Curing Spells for Improvised Utility Blocks. The experimentation on replacement of treated effluent ranging from 3\% to 15\% takes forward the temporal variations in compressive strength to a reasonable height. The eventual optimal replacement percentages of dried fly ash sediment for cement are fixed as 9\% under the statistical regression analysis. Figure 7 depicts a linear variation trend in compressive strength values by prediction with the cumulatively increasing curing spells.

The graphical plot represented a highly dependable correlation at $R^{2}=0.905$; the mathematical relationship between the compressive strength and curing spells of the improvised block was reckoned as $y=0.505 x+16.766$. The base compressive strength obtained from the empirical equation by backward projection was found to be $16.76 \mathrm{MPa}$. The compressive strength indicated a steady increasing rate

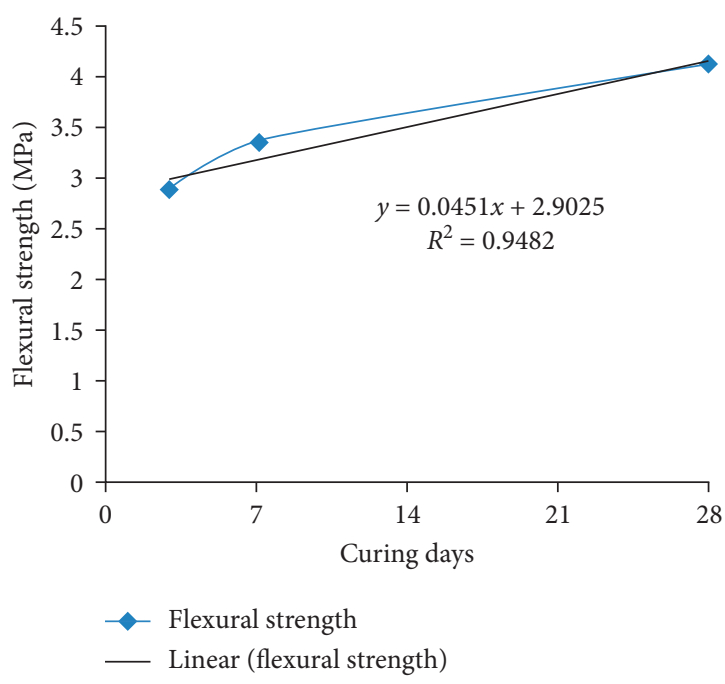

FIgURE 5: Temporal variations in flexural strength of the conventional concrete block.

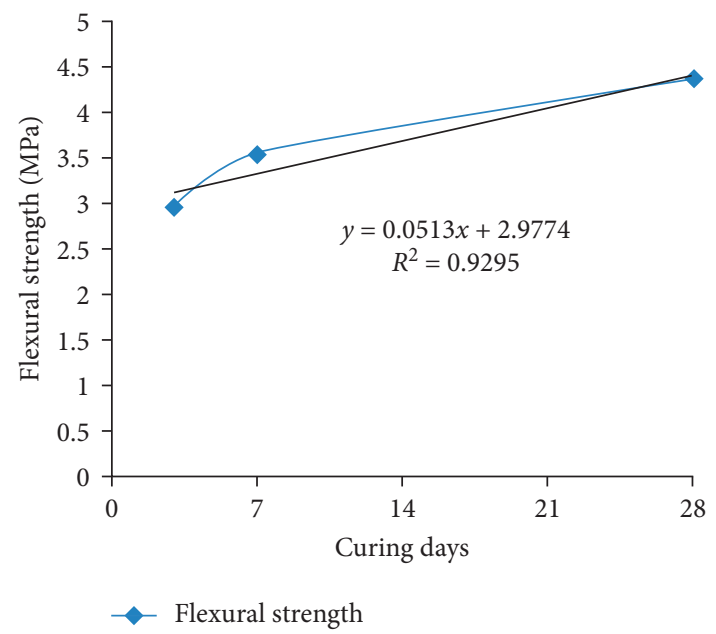

FIgURE 6: Temporal variations in flexural strength of treated effluent imbibed concrete block.

of $0.505 \mathrm{MPa}$ per day, which is slightly higher than that of control concrete blocks. Following the empirical regression path, the improvised concrete mix could end up with the maximum compressive strength of $30.8 \mathrm{MPa}$ at the end of 28 days nominal curing spell against the stipulated design value of $30 \mathrm{MPa}$. It implies that the design strength got accelerated to reach its value of $30 \mathrm{MPa}$ at the end of 26 days, well before the end of the nominal 28 days. Comparing this with the control concrete mix that could reach a predicted maximum of $30.5 \mathrm{MPa}$, the strength realizable by the improvised concrete was found to be on par. Simultaneously on the other side, the base compressive strength at the new state of the concrete and the subsequent rates of change were slightly different from each other.

3.5. Flexural Strength Compared with Curing Spells for Improvised Utility Blocks. The regression path prediction in line with the compressive strength analysis, the variations in 


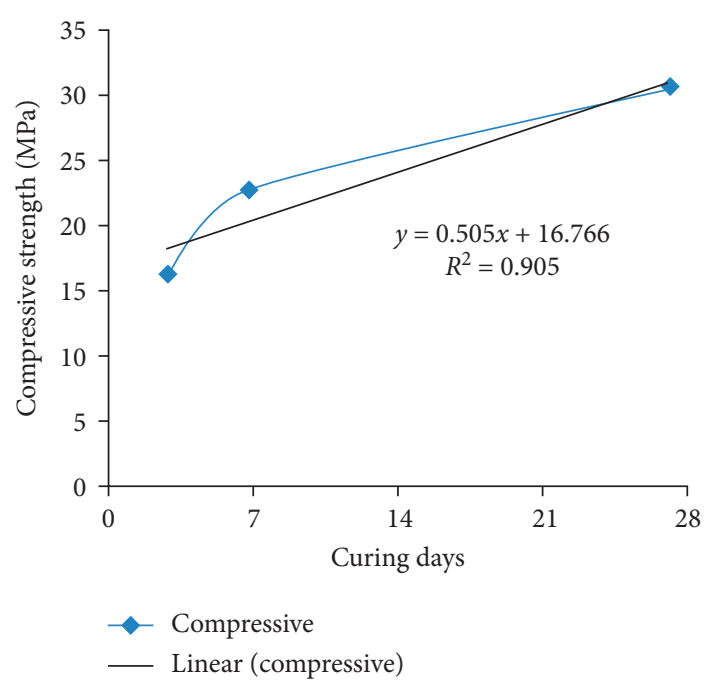

FIGURE 7: Temporal variations in compressive strength of treated effluent imbibed concrete block.

the flexural strengths attainable concerning the curing time lapses ranging from 0 to 28 days were also experimented upon. Figure 8 illustrates the critical temporal variations in the flexural strength of the improvised concrete, the empirical regression equation being $y=0.0559 x+2.985$, the data scatter getting a reliable correlation level at $R^{2}=0.9102$ (the regression logic has effectively used $91 \%$ of the observed data to get at the prediction equation, $9 \%$ of the data lying beyond at the regression range). The predicted 28-day flexural strength is identified as $4.55 \mathrm{MPa}$ near the real value of 4.38 MPa obtained from the experimentation [30, 31].

3.6. SEM Analysis. The microstructure of the cement mantle of conventional and improvised concrete was analyzed using SEM images. In the conventional concrete matrix, the microlevel SEM analysis indicated a sporadic distribution of the molecules explicitly showing the widened pores. In case of improvisation with treated effluent and dried fly ash sediment addition, in addition to the partial replacement of cementitious matter, significant filler effects were also added upon. In the SEM analysis, the micro close-up view has revealed a relatively denser cumulated cloud-like formation is indicating the narrowed-down pores. The reduction in porosity strengthens the improvised blocks in the facets of microstructural pore densification and in restricting the crack propagation [15]. Scanning Electron Microscopy analysis also revealed that the improved blocks could meet a cloud-like microstructure that is more stable than the sporadic and porous scatter of molecules of conventional concrete mix as shown in Figure 9.

After 28-day curing, the completely dried concrete blocks show significant strength and structure. In this case, the formation of pores and low thermal conductivity prevalence are dependent on the mechanical properties of the mix ratio of admixture. The SEM analysis of the concrete highlighted the hydration property, the development of pore

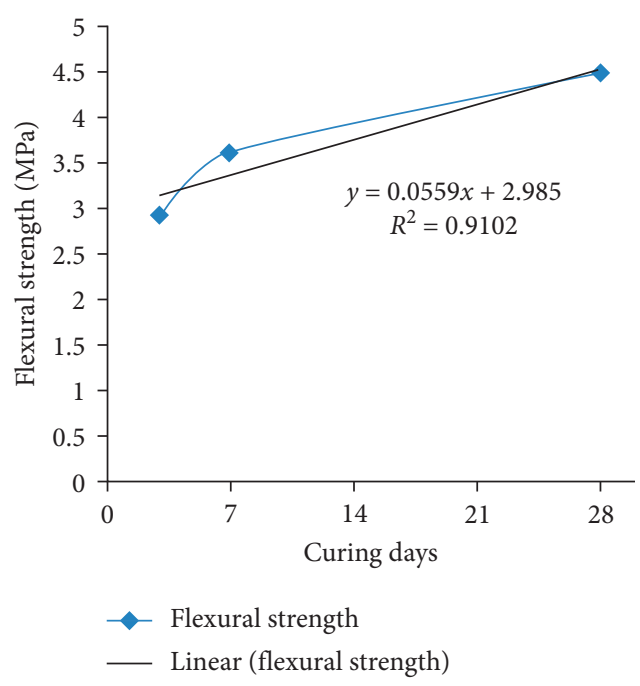

FIgURE 8: Temporal variations in flexural strength of the improvised concrete block.

after complete curing displayed improved pore size, and this might be due to the change in weather condition that is supported by the foundation of dye wastewater. The sizes of pore in the concrete are based on mix proportion of base material supported by mechanical properties and heat transfer rate [32]. Similar work has been carried out in fabricating aerogels and the outcomes are highlighted in such a way that temperature and environmental conditions are deciding factors for change in porosity and stability of thermal insulation [33].

3.7. Cost Analysis. In this work, the waste product of thermal power plants fly ash is converted as raw material for constructing construction industry commercial utility blocks. The optimizations of fly ash in this experimentation are identified as $25 \%$. Considering the parameter in terms of weight, $25 \mathrm{~kg}$ of fly ash and appropriate dye effluent used are 100 liters, which are proved to be effective in the product load test. The total cost per Indian currency, including material and power utilized for treatment, is evaluated as 30 rupees. Compared with other conventional treatments method, it is observed to be $60 \%$ cheaper. Utilizing fly ash as a coagulant reduces the cost as well as environmental pollution.

3.8. Constructed Wetland Model. A comparative study on constructed wetland and a sequential batch reactor (SBR) was performed based on an industrial wastewater treatment unit's economic and environmental costs analysis. The financial results points towards implementing CWs are between the savings; meanwhile, implementing SBR leads to excessive wastage of considerable capital. The Life Cycle Assessment (LCA) Study insists on lower energy usage and material uptake, leading to lower eutrophication. The pilotscale model designs are highlighted in Figure 10. 


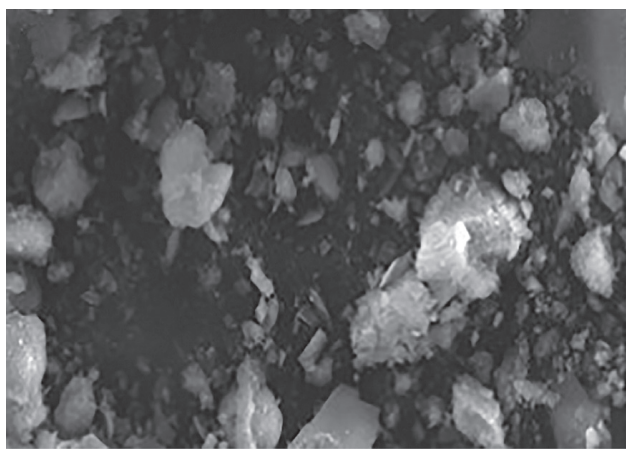

(a)

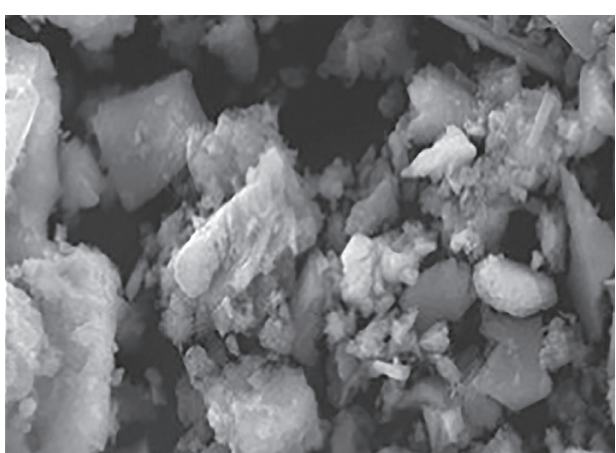

(b)

FIgURE 9: Microstructure of cement mantle at 5,000-time magnification. (a) Conventional blocks. (b) Improvised blocks.

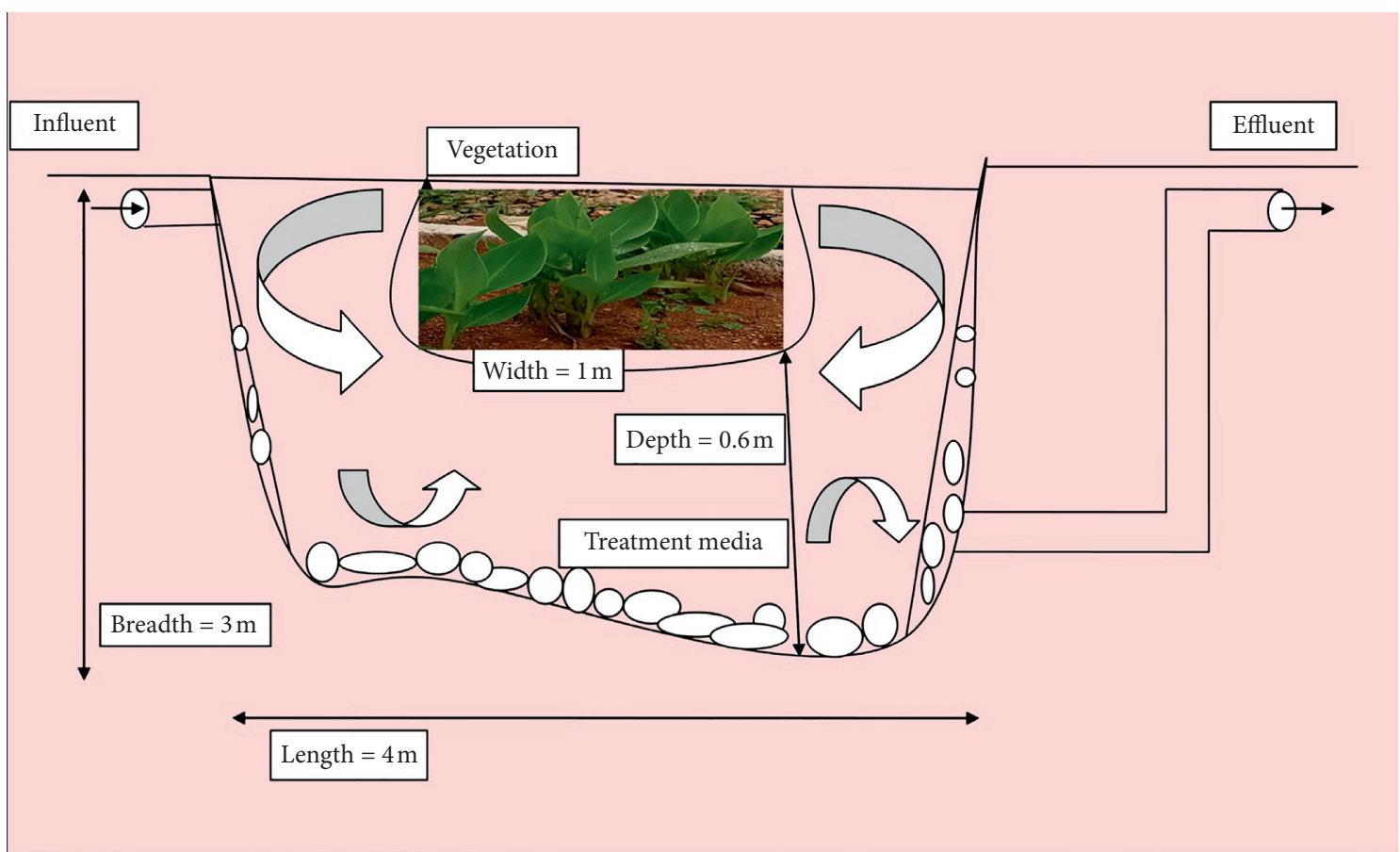

Figure 10: Design of constructed wetland to treat dye effluent.

3.9. Economical Consideration of CW for Treating Industrial Wastewater. A comparative study on constructed wetland and a sequential batch reactor (SBR) was performed based on the economic and environmental costs analysis from an industrial wastewater treatment unit by DiMuro et al. (2014). It was observed that the storm water is also routed through the system and the financial results points towards implementing CWs are between the savings; meanwhile, implementing SBR leads to excessive wastage of multiple of capital amount [34]. The Life Cycle Assessment (LCA) study insists on lower energy usage and material uptake that lead to lower eutrophication [35].

The investment on concrete blocks is reasonable and less compared with conventional concrete blocks as in our case the admixtures fly ash and dye effluent sludge are no-cost resources. The transportation on dye effluent is negligible as in our case a large number of treatment units are available in nearby premises. Sludge dry cake can be a diluted to waste product and wastewater for effective processing. The natural treatment on the constructed wetland does not require any additional cost for improving the efficiency in terms of maintenance. The process works under natural filtration that removes pollution which may be adaptable in rural, urban in all sorts of sizes. The cost of invest for concrete blocks normally ranges around 3000 rupees; meanwhile, the engineered construction wetland with surface flow fixation ranges around 8000 rupees for a small unit, which is highlighted in Figure 10.

The life cycle assessment in terms of economic and environmental benefit for constructed wetland and sequential batch reactor highlights a significant difference. In case of constructed wetland debris and recyclable materials are used where in case of sequential batch reactor material usage are higher. The removal efficiency of wetland shows 
significant improvement than SBR. Similarly there is no operation and maintenance cost for wetland [36].

\subsection{Cost Analysis}

3.10.1. Transportation. Considering the shifting of raw materials from the source unit to the treatment unit, the transportation cost has been finalized; in this context, using least cost analysis and life cycle assessment, the total cost has been predicted and presented in Table 4 .

3.10.2. Wastewater Treatment. Regarding the treatment of wastewater, multidimensional attention has been focused on evaluating the cost in a step-by-step process focusing on cost-effective extension. Based on economic assessment formulas, the results have been scheduled.

The material cost, the treatment cost, the life term continuation cost, and service cost have been calculated based on the below mentioned formulas.

$$
C C=C_{i n i}+C_{o p}+C_{m}+C_{e n}+C_{i n d}-C_{r v} .
$$

The capital cost comprises a summation of initial startup, operation, maintenance, energy, and independent cost, where the remaining value of investment is removed:

$$
P V=\frac{F V}{(1+r)^{n}}
$$

Considering the flow and treatment volume for the designed unit, the present value is predicted. The future value is essential for flow measurement and return is measured for number of periods:

$$
\begin{aligned}
& F C=P C(1+I)^{n}, \\
& P C=F C(1+i)^{n} .
\end{aligned}
$$

The future cost is estimated based on present cost subjected to inflation cost for number of periods. Similarly the present cost is predicted based on the rate of interest:

$$
\begin{gathered}
M C=A_{m c} \frac{(1-F)^{n}}{1}, \\
F-1 \\
F=\left(\frac{1+I}{1+i}\right)^{n} .
\end{gathered}
$$

The maintenance cost is estimated based on the annual maintenance subjected to number of years; meanwhile, the value of $F$ represents the data corresponding to inflation and interest rate.

From observation, it is clear that the economy on designing the constructed wetland has been the most costeffective strategy, which may be adaptable in rural usage. This work has a lot of potential for extension of the treatment unit by varying hybrid flows.
3.11. Comparison of Life Cycle Assessment on CWs and SBR. In treating wastewater for a cubic meter, the land requirement for constructed wetland is three square meters. In case of sequential batch reactor, the occupancy level is significantly lesser with one square meter, which is preferred mostly in the urban areas, and in case of constructed wetland, more attentions are focused in the rural areas. Considering the strength of structure constructed, fiber reinforced concrete has been used in SBR which comprises of steel bar, and considering the life assessment, utilization of fossil fuels for mining work has recorded higher priority. Meanwhile, CWs are constructed using environmentally friendly materials with no harm to the ecology.

The utilization of machinery for the implementation of SBR has been $4.4 \%$ which runs on fuels and electricity that cost $30.9 \%$ of the total energy. Taking into consideration the process of fuel and electricity generation for successful operation of one cubic meter wastewater, the SBR records emission of $0.72 \mathrm{~kg}$ sewage and $0.21 \mathrm{~kg}$ solid waste that excludes the general maintenance incurred in running the unit that took $17.5 \%$ of energy excluding the transportation cost. In case of constructed wetland, it is natural process with no energy utilization followed by zero operation and maintenance.

$$
\mathrm{EWRE}=\frac{\text { total energy cost in waste treatment }}{\text { waste removal }} .
$$

The ecological waste removal efficiency of both the treatment units SBR and CWs has been evaluated with this equation and based on the outcome the life cycle assessment has been predicted.

This study highlights that the wastewater is a natural resource which has large quantum of nutrients and water that may be utilized in a productive ecosystem favoring the microbial reactions. As a concluding remark, the process will be effective if life term of the treatment units is prolonged and this is based on economy, which should be picked wisely.

\subsection{Concrete Block}

3.12.1. Limitations. In this work, the manufacturing of concrete block has been evolved with a combination of additives such as fly ash and textile dye sludge. In general, the sustainability of any product in the construction industry depends on available source of raw material, potential for manufacturing, and managing the waste material to the extent; these parameters determine the life cycle in commercial market. For the first time, the percentage utilization of textile dye effluent has been experimented in manufacturing concrete block and its efficiency has been evaluated by utilization in building an artificial constructed wetland. This study matches all the key parameters such as strength, durability as conventional concrete block and highlighted to be an eye opening for strategy deriving in the field of the waste management. 
TABLE 4: Cost analysis for treatment of one cubic meter wastewater.

\begin{tabular}{lcccc}
\hline S. no. & \multicolumn{2}{c}{ Constructed wetland } & \multicolumn{2}{c}{$\begin{array}{c}\text { Sequential batch reactor (SBR) } \\
\text { Least cost analysis }\end{array}$} \\
\hline 1 & Least cost analysis & Value & Cement bag, Rs. 412 & Value \\
2 & Cement bag, Rs. 412 & 824 & Brick, Rs. 8 & S10 \\
3 & Brick, Rs. 8 & 4000 & Sand load, Rs. 680/unit & 820 \\
4 & Sand load, Rs. 680/unit & 2720 & Coarse aggregate, Rs. 1.57/kg & 435 \\
5 & Coarse aggregate, Rs. 1.57/kg & 1570 & Paint, Rs. 250/litre & 200 \\
6 & Paint, Rs. 250/litre & 500 & Labour, Rs. 700/day & 1500 \\
7 & Labour, Rs. 700/day & 2100 & Machinery (periodical) & 45,600 \\
8 & Machinery (periodical) & 300 & Energy (fuel and electricity) & 8955 \\
9 & Energy (fuel and electricity) & 600 & Cost estimated & $59,620 /-$ \\
\hline
\end{tabular}

3.12.2. Difficulties. In achieving a reasonable strength, the design parameters have been randomized, the mix proportion has been closely monitored; the economy of each model has been assessed. Optimized data has been fixed as standard and satisfies safety margins. The usage of alternative material has been a challenging task during the experimentation stage and checking the strength.

3.12.3. Applications. The local authority may approve the proposed outcome for commercialization of the product in construction industry especially for the treatment of wastewater, manufacturing sewer pipes, and all sorts of works related with waste treatment.

\section{Conclusion}

An environmentally friendly approach is adapted with waste products, dye effluent, and fly ash to manufacture utility blocks. This typical trial and error-based experimentation in fixing the ideal proportional combinations of dry-fly ash sediments along the total replacement of the potable water by the treated effluents gives a considerable outcome for the modern construction industry. A right regression analysis at the macrolevel is analyzed and distinguishes the partial substitution proportions like $25 \%$. From observation, the conventional potable water can be replaced by the properly treated dye effluents without harm to the quality criteria desired. CWs are monitored to be the admired alternative technologies with zero operational trouble for dye effluent treatment rather than conventional-type wastewater treatment.

\section{Data Availability}

The data used to support the findings of this study are included in the article.

\section{Additional Points}

Study on pretreatment methods, planting on new vegetation, introducing different porous media, and change in operational strategy are the research areas where future investigation is to focus on potential innovative applications associated with CWs and commercialization of new concrete blocks.

\section{Conflicts of Interest}

The authors declare that there are no conflicts of interest regarding the publication of this article.

\section{References}

[1] C. Stone, F. M. Windsor, M. Munday, and I. Durance, "Natural or synthetic-how global trends in textile usage threaten freshwater environments," The Science of the Total Environment, vol. 718, Article ID 134689, 2020.

[2] R. Dharmaraj, "Experimental study on strength and durability properties of iron scrap with flyash based concrete," Materials Proceedings, vol. 37, pp. 1041-1045, 2020.

[3] H. Zhou, L. Zhou, and K. Ma, "Microfiber from textile dyeing and printing wastewater of a typical industrial park in China: occurrence, removal and release," The Science of the Total Environment, vol. 739, Article ID 140329, 2020.

[4] M. I. Alfa, H. I. Owamah, A. O. Onokwai et al., "Evaluation of biogas yield and kinetics from the anaerobic co-digestion of cow dung and horse dung: a strategy for sustainable management of livestock manure," Energy, Ecology and Environment, 2020.

[5] H. Owamah, M. Alfa, O. Solomon, and P. C. Emenike, "Groundwater quality monitoring and perception issues in a popular niger delta university town in nigeria," Groundwater for Sustainable Development, vol. 12, Article ID 100503, 2020.

[6] S. Gopikumar, S. Raja, Y. H. Robinson, V. Shanmuganathan, H. Chang, and S. Rho, "A method of landfill leachate management using internet of things for sustainable smart city development," Sustainable Cities and Society, vol. 66, Article ID 102521, 2021.

[7] M. Joemax Agu, S. Gopikumar, S. Vimal, and Y. Harold Robinson, "Failure assessment of pressure vessels made of plain carbon steel by using modified inherent flaw model in DL based industry optimization intelligent processing," Measurement, vol. 165, Article ID 108112, 2020.

[8] R. Dharmaraj and G. Iyappan, "Suitability of partial replacement of pulverized plastic as fine aggegate in cement concrete," Indian Journal of Science and Technology, vol. 9, no. 23, pp. 1-6, 2016.

[9] M. Dinesh Kumar, S. Gopikumar, D. Khac Uan, S. Adishkumar, and J. Rajesh Banu, "Constructed wetland: an emerging green technology for the treatment of industrial wastewaters," Emerging Eco Friendly Green Technologies for Wastewater treatment, vol. 2, pp. 978-981, 2020.

[10] A. H. Noruzman, B. Muhammad, M. Ismail, and Z. AbdulMajid, "Characteristics of treated effluents and their potential 
applications for producing concrete," Journal of EnvironMental Management, vol. 110, pp. 27-32, 2012.

[11] A. S. Al-Harthy, R. Taha, J. Abu-Ashour, K. Al-Jabri, and S. Al-Oraimi, "Effect of water quality on the strength of flowable fill mixtures," Cement and Concrete Composites, vol. 27, no. 1, pp. 33-39, 2005.

[12] S. A. Paul, S. K. Chavan, and S. Khambe, "Studies on characterization of textile industrial waste water in Solapur City," International Journal of Chemical Sciences, vol. 2, pp. 635-642, 2012.

[13] B. J. Zhan and C. Sun Poon, "Study on feasibility of reutilizing textile effluent sludge for producing concrete blocks," Journal of Cleaner Production, vol. 101, pp. 174-179, 2015.

[14] T. Raghunathan, P. Gopalsamy, and R. Elangovan, "Study on strength of concrete with ETP sludge from dyeing industry," International Journal of Civil and Structural Engineering, vol. 1, no. 3, pp. 379-389, 2010.

[15] O. S. Lee, M. R. Salim, M. Ismail, and M. I. Ali, "Reusing treated effluent in concrete technology," Jurnal Teknologi, vol. 34, pp. 1-10, 2001.

[16] C. M. Noorjahan, "Physicochemical characterization of untreated textile effluent and its effects on biochemical constituents of fresh water fish, Tilapia Mossambica," Indian Streams Research Journal, vol. 1, pp. 1-11, 2011.

[17] P. Hema and P. Suneel, "Exploring the reuse potential of chemical sludge from textile wastewater treatment plants in India-A hazardous waste," American Journal of Environmental Sciences, vol. 5, no. 1, pp. 106-110, 2009.

[18] B. Chatveera, P. Lertwattanaruk, and N. Makul, "Effect of sludge water from ready-mixed concrete plant on properties and durability of concrete," Cement and Concrete Composites, vol. 28, no. 5, pp. 441-450, 2006.

[19] L. Soto-Pérez and S. Hwang, "Mix design and pollution control potential of pervious concrete with non-compliant waste fly ash," Journal of Environmental Management, vol. 176, pp. 112-118, 2016.

[20] B. J. Sealey, J. Hillg, and P. Phillips, Review of Strategy for Recycling and Reuse of Waste Materials, Institution of Civil Engineers, London, UK, 2002.

[21] G. K. Arunvivek and D. Rameshkumar, "Experimental investigation on performance of waste cement sludge and silica fume-incorporated portland cement concrete," Journal of The Institution of Engineers (India): Series A, vol. 100, no. 4, pp. 611-618, 2019.

[22] J. Balasubramanian, P. C. Sabumon, J. U. Lazar, and R. Ilangovan, "Reuse of textile effluent treatment plant sludge in building materials," Waste Management, vol. 26, no. 1, pp. 22-28, 2006.

[23] T. Hussain and A. Wahab, "A critical review of the current water conservation practices in textile wet processing," Journal of Cleaner Production, vol. 198, pp. 806-819, 2018.

[24] S. B. Megdal, "Invisible water: the importance of good groundwater governance and management," NPJ Clean Water, vol. 1, no. 1, pp. 1-5, 2018.

[25] B. Grizzetti, A. Pistocchi, C. Liquete, A. Udias, F. Bouraoui, and W. Van De Bund, "Human pressures and ecological status of European rivers," Scientific Reports, vol. 7, pp. 1-11, 2017.

[26] BIS IS 456, Plain and Reinforced Concrete-Code of Practice, Bureau of Indian Standards (BIS), Manak Bhawan, India, 2000.

[27] V. Dobilaitè, M. Sacevičienè, and V. Saceviciene, "Study of textile waste generation and treatment in Lithuania," Fibres and Textiles in Eastern Europe, vol. 25, pp. 8-13, 2017.
[28] R. Dharmaraj and R. Malathy, "Performance evaluation of sodium nitrite corrosion inhibitor in self com-pacting concrete," Indian Journal of Science and Technology, vol. 8, no. 36, pp. 1-6, 2015.

[29] J. J. Long, H. M. Xu, C. L. Cui, X. C. Wei, F. Chen, and A. K. Cheng, "A novel plant for fabric rope dyeing in supercritical carbon dioxide and its cleaner production," Journal of Cleaner Production, vol. 65, pp. 574-582, 2014.

[30] M. Banchero, "Supercritical fluid dyeing of synthetic and natural textiles-a review," Coloration TechNology, vol. 129, no. 1, pp. 2-17, 2013.

[31] R. Dharmaraj and B. Sivakumar, "A feasibility study on cement with addition of Prosopis Juliflora ash as in concrete," Materials Today: Proceedings, vol. 37, pp. 1212-1217, 2020.

[32] G. Chen, F. Li, P. Jing, J. Geng, and Z. Si, "Effect of pore structure on thermal conductivity and mechanical properties of autoclaved aerated concrete," Materials, vol. 14, no. 2, p. 339, 2021.

[33] S. Jiang, M. Zhang, M. Li, L. Liu, and J. Yu, "Cellulose nanofibril (CNF) based aerogels prepared by a facile process and the investigation of thermal insulation performance," Cellulose, vol. 27, p. 1, 2020.

[34] S. Gopikumar, S. Sundararajan, J. A. K. Gladston, C. A. V. Kumar, and K. H. Babu, "A quantitative study of hydraulic parameters of Thamirabarani river," Austin Journal of Environmental Toxicology, vol. 7, no. 1, p. 1034, 2021.

[35] M. Varma, A. K. Gupta, P. S. Ghosal, and A. Majumder, "A review on performance of constructed wetlands in tropical and cold climate: insights of mechanism, role of influencing factors, and system modification in low temperature," The Science of the Total Environment, vol. 755, Article ID 142540, 2021.

[36] W. Wang, T. Yang, W. Guan et al., "Ecological wetland paradigm drives water source improvement in the stream network of Yangtze River Delta," Journal of Environmental Sciences, pp. 1-19, 2021. 